\title{
Validation of the CERES Edition-4A Surface-Only Flux Algorithms
}

\author{
DAVID P. KRATZ \\ Science Directorate, NASA Langley Research Center, Hampton, Virginia \\ Shashi K. Gupta, ANne C. Wilber, AND Victor E. SothCotT \\ Science Systems Applications, Inc., Hampton, Virginia
}

(Manuscript received 22 March 2019, in final form 16 December 2019)

\begin{abstract}
Surface radiative fluxes have been derived with the objective of supplementing top-of-atmosphere (TOA) radiative fluxes being measured under NASA's Clouds and the Earth's Radiant Energy System (CERES) project. This has been accomplished by using combinations of CERES TOA measurements, parameterized radiative transfer algorithms, and high-quality meteorological datasets available from reanalysis projects. Current CERES footprint-level products include surface fluxes derived from two shortwave (SW) and three longwave (LW) algorithms designated as SW models A and B and LW models A, B, and C. The SW and LW models A work for clear conditions only; the other models work for both clear and cloudy conditions. The current CERES Edition-4A computed surface fluxes from all models are validated against ground-based flux measurements from high-quality surface networks like the Baseline Surface Radiation Network and NOAA's Surface Radiation Budget Network (SURFRAD). Validation results as systematic and random errors are provided for all models, separately for five different surface types and combined for all surface types as tables and scatterplots. Validation of surface fluxes is now a part of CERES processing and is used to continually improve the above algorithms. Since both models B work for clear and cloudy conditions alike and meet the accuracy requirement, their results are considered to be the most reliable and most likely to be retained for future work. Both models A have limited use given that they work for clear skies only. Models B will continue to undergo further improvement as more validation results become available.
\end{abstract}

\section{Introduction}

Changes in the radiation budget of the Earthatmosphere system, both at the surface and at the top of the atmosphere (TOA), are the first indicators of the perturbation of climate caused by humaninduced changes in greenhouse gases, aerosols, and other environmental factors (Wild and Roeckner 2006). Estimates of the components of radiation budget at the surface and at the TOA were identified by the Global Climate Observing System (GCOS) as essential climate variables (GCOS 2003). The NASA Clouds and the Earth's Radiant Energy System (CERES) is a satellite project designed for deriving accurate estimates of those Earth radiation budget parameters for use in investigations of the climate system and

Corresponding author: Dr. David P. Kratz, david.p.kratz@ nasa.gov. cloud-radiation interactions (Loeb et al. 2018; Wielicki et al. 1996). Shortwave (SW) and longwave (LW) radiative fluxes at the TOA are derived from corresponding radiances directly measured by CERES instruments. Surface radiative fluxes, which, along with fluxes of latent and sensible heat, constitute the surface energy budget, are not directly measurable from satellites, although they are just as essential for climate system studies as TOA fluxes (Kato et al. 2013; Wild et al. 1995). In view of such a need, combinations of TOA measurements, radiative transfer models, and high-quality meteorological datasets available from reanalysis projects have been used for developing algorithms for deriving surface radiative fluxes (Rose et al. 2013; Kato et al. 2018). Two SW (Li et al. 1993a,b; Gupta et al. 2001) and three LW (Inamdar and Ramanathan 1997; Gupta et al. 1992; Zhou et al. 2007) algorithms from among these are currently being used within the surface-only flux algorithms (SOFA) 
segment of CERES processing and are respectively labeled as SW models A and B and LW models A, B, and $\mathrm{C}$. These algorithms produce two $\mathrm{SW}$ and three LW flux estimates on an instantaneous-footprint basis for each scanning instrument and are all provided in the CERES Single Scanner Footprint (SSF) product. Validation of these fluxes against groundbased flux measurements and intercomparison among products of different algorithms is helpful in assessing their strengths and weaknesses and identifying the most robust among them. The purpose for the use of several algorithms at the same time and the extensive validation is to identify the best algorithms among them.

CERES project has launched seven instruments on five separate low-Earth-orbiting satellites starting with the preflight model (PFM) on the Tropical Rainfall Measuring Mission (TRMM) in November 1997, followed by flight models 1 and 2 (FM1 and FM2) on Terra in December 1999, FM3 and FM4 on Aqua in May 2002, FM5 on Suomi National Polar-Orbiting Partnership (Suomi-NPP) in October 2011, and FM6 on Joint Polar Satellite System-1 (JPSS-1)/NOAA-20 in November 2017. PFM was deorbited in June 2015, and FM1-FM5 are currently producing data. FM6 data are presently going through the calibration/validation phase. Each instrument on Terra, Aqua, and Suomi-NPP (FM1FM5) has scanning radiometers with three spectral channels defined as the total $(0.2-200 \mu \mathrm{m})$, SW $(0.2-$ $5 \mu \mathrm{m})$ window, and LW $(8-12 \mu \mathrm{m})$ window. The LW window channel on FM6 has been replaced by a broadband LW $(5-100 \mu \mathrm{m})$ channel. Results from Terra and Aqua instruments constitute the longest data record and have undergone the most extensive characterization and calibration (Loeb et al. 2016). Also, these data have gone through progressively refined editions of the CERES processing system. The current version of the system used with Terra and Aqua data is designated as Edition 4A. Imager data from the Moderate Resolution Imaging Spectroradiometer (MODIS) that flies aboard both Terra and Aqua are used for deriving cloud properties (Menzel et al. 2008; Minnis et al. 2010) and scene identification information (Loeb et al. 2005; Su et al. 2015a,b) required for surface and TOA flux computations.

CERES-derived SSF data have been intercompared with one another and extensively validated using surface-based flux measurements collected from highquality networks like the Baseline Surface Radiation Network (BSRN) and NOAA's Surface Radiation Budget Network (SURFRAD). This paper presents validation of SSF fluxes from each algorithm separately for clear and cloudy footprints. Clear footprints are defined here as those with $<0.1 \%$ cloud amount with all others defined as cloudy. Section 2 presents brief descriptions of the algorithms and input data sources. These algorithms were chosen for processing and validation at the recommendation of the CERES Science Team (CST) and can be removed only on a CST recommendation. Section 3 presents a discussion of the sources of surface validation data. Results of those intercomparisons and validation are presented in section 4 , followed by summary and conclusions in section 5 .

\section{Surface flux models and input data}

Numerous improvements have been incorporated into some of these models since their initial application to CERES processing. Such improvements are a direct consequence of the continual validation of SOFA SSF products (Gupta et al. 2004; Kratz et al. 2010). Only details of those model improvements will be provided in this section. Other models will be only briefly mentioned since adequate description of those has been presented in earlier publications (e.g., Kratz et al. 2010). For example, SW model A proposed by Li et al. (1993a,b) is a linear parameterization for estimating net SW surface flux. Downward SW flux (DSF) was to be derived by using surface albedo values from $\mathrm{Li}$ and Garand (1994). Although considered promising at the time it was introduced, it produces clear-sky surface net SW fluxes only and has remained that way without any further enhancements. LW model A proposed by Inamdar and Ramanathan (1997) derives broadband downward LW flux (DLF) at the surface as a sum of its components in the $8-12-\mu \mathrm{m}$ window and the nonwindow regions by making use of the window region TOA measurements from CERES instruments. This model was also a clear-sky-only model at the time of introduction and remained so without any further improvements. SW and LW models B are both all-sky models and have undergone substantial improvements over the years. LW model $\mathrm{C}$ is newly introduced in CERES with Edition-4A processing. Improvements made to these models are separately described below.

\section{a. SW model B}

The SW model B is also known as the Langley parameterized shortwave algorithm (LPSA), which derives downward SW flux (DSF) as

$$
F_{0}=S_{0} d^{-2} \mu T_{a} T_{c},
$$

where $S_{0} d^{-2} \mu$ together represent the incoming solar irradiance at the TOA and $T_{a}$ and $T_{c}$ represent atmospheric 
and cloud transmittances computed separately. A comprehensive description of LPSA is available in Gupta et al. (2001) and Kratz et al. (2010).

The LPSA model has undergone a number of significant improvements since the Kratz et al. (2010) study on CERES Edition-2B results. For example, the clear-sky surface albedo climatology used in DSF computation has been updated several times using newer editions of CERES clear-sky measurements (unpublished results). These updates substantially improved the agreement between CERES-derived DSF with ground-based measurements, especially at polar sites (Kratz et al. 2010). Another important improvement made to the LPSA model since the Edition-2B processing was the replacement of the original World Climate Programme (WCP)-55 aerosol properties (Deepak and Gerber 1983). This was initially accomplished by using a monthly climatology of aerosol optical depths (AODs) derived from 10 years of the Model for Atmospheric Transport and Chemistry (MATCH; Collins et al. 2001; Rasch et al. 1997) data, and subsequently by near-real-time daily AODs, also from MATCH. Corresponding values of single scattering albedo and asymmetry parameter were derived from the Optical Properties of Aerosols and Clouds (OPAC) database (Hess et al. 1998). The use of daily aerosol properties has allowed for the effects of transient aerosol events to be captured in the derived SSF fluxes.

\section{b. LW model B}

This model makes use of the Langley parameterized longwave algorithm (LPLA) as initially outlined in Gupta (1989) with revisions presented in Gupta et al. (1992) for computing DLF. By incorporating the surface emissivity map (Wilber et al. 1999), upward and net surface fluxes can be computed from downward fluxes. A more detailed discussion of the LPLA model is provided in Kratz et al. (2010).

As with the LPSA, the LPLA model has also undergone two important improvements since its use in the Edition2B processing. Validation of the LPLA-derived DLF over arid sites, especially during daytime, revealed substantial overestimations in the DLF. Further analysis showed that these overestimations occurred when surface skin temperature far exceeded the temperature of the atmospheric layers just above the surface, causing the temperature lapse rates near the surface to be unsustainably high. Detailed discussion of this problem and a formulated solution were presented in Gupta et al. (2010). The solution consisted in limiting the temperature lapse rate between the surface and the lowest atmospheric layer close to the adiabatic lapse rate of $\approx 10 \mathrm{~K} \mathrm{~km}^{-1}$.
Another problem observed during the validation of DLF over polar regions, especially for Antarctica, caused an effect that was exactly opposite to that described above, where substantial underestimations occurred when the surface skin temperature was much lower (by 20-30 K) than the temperature of the lowest atmospheric layers. This condition occurred frequently over polar and high-altitude regions where extremely low water vapor amounts allowed the surface to radiate essentially directly to space and surface temperature to plummet. This situation was remedied by limiting the temperature lapse rate to $-10 \mathrm{~K} \mathrm{~km}^{-1}$, a value chosen after considerable numerical experimentation.

\section{c. LW model C}

This model is based on work reported in Zhou and Cess (2001) and Zhou et al. (2007). It was incorporated into the SOFA SSF processing because the CERES FM6 instrument, which is now flying aboard the JPSS-1/NOAA-20 satellite, has been modified by replacing the $8-12-\mu \mathrm{m}$ window channel by a broadband $(5-100 \mu \mathrm{m}) \mathrm{LW}$ channel, thereby rendering the LW model A inoperative with the FM6 data. The early version of this model (Zhou and Cess 2001) demonstrated that clear-sky DLF can be represented in terms of surface upward LW flux (ULF) and column water vapor. That version was revised later based on the results of validation studies and also extended to cover cloudy-sky conditions (Zhou et al. 2007). Separate expressions were developed for the clear-sky component,

$$
F_{0, L, \mathrm{clr}}^{-}=a_{0}+a_{1} \mathrm{ULF}+a_{2} \ln (1+w)+a_{3} \ln (1+w)^{2}
$$

where $w$ is the column water vapor, $a_{0}-a_{3}$ are regression coefficients, and ULF is the upward LW flux computed with surface skin temperature and surface emissivity of unity, and the cloudy-sky component,

$$
\begin{aligned}
F_{0, L, \mathrm{cld}}^{-}= & b_{0}+b_{1} \mathrm{ULF}+b_{2} \ln (1+w)+b_{3} \ln (1+w)^{2} \\
& +b_{4} \ln (1+\operatorname{lwp})+b_{5} \ln (1+\mathrm{iwp}),
\end{aligned}
$$

where lwp and iwp are the liquid and ice water paths present in the cloud, respectively, and $b_{0}-b_{5}$ are regression coefficients. Total DLF was then computed as the sum of clear and cloudy components weighted by their respective fractions.

\section{d. Input data}

The input parameters necessary to run the SW and LW models have been obtained from the CERES 


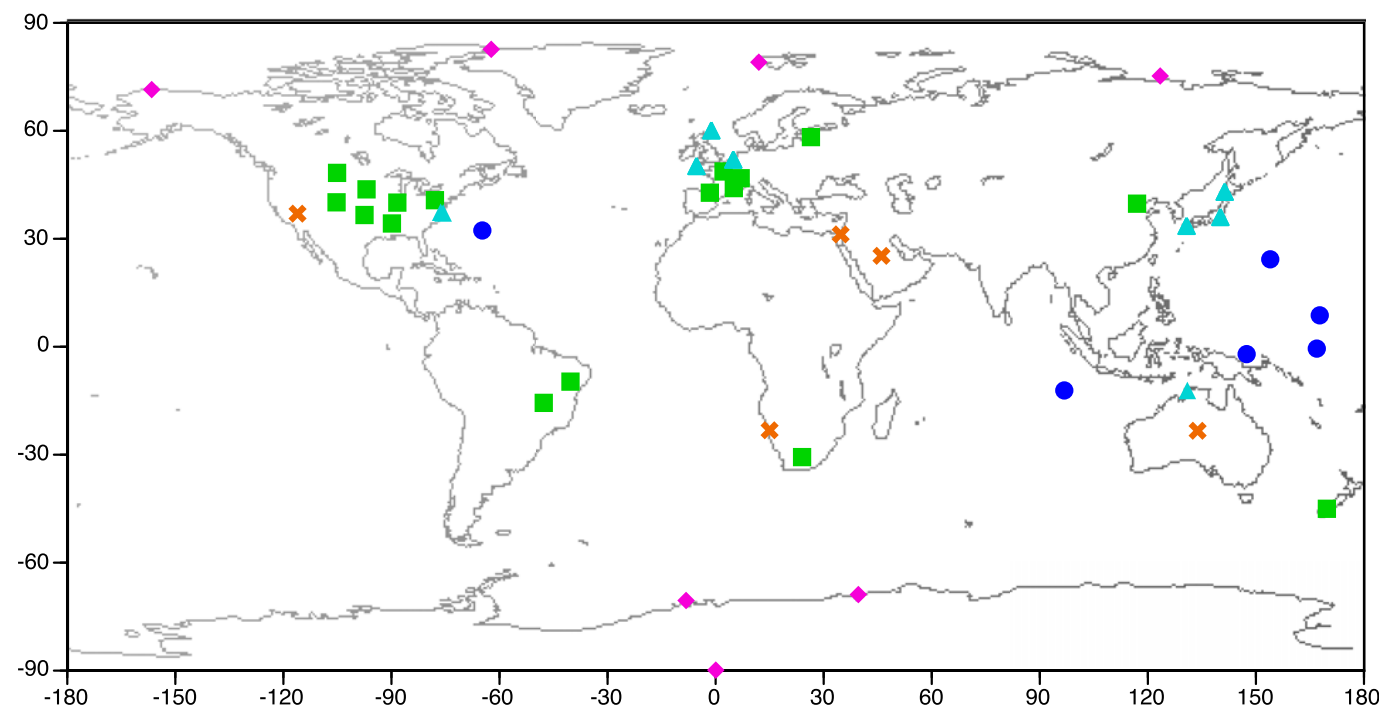

FIG. 1. Distribution and surface type for the 44 surface sites considered in this study. The various symbols represent different surface types as follows: islands $(\bullet)$, coastal $(\mathbf{\Lambda})$, polar $(\bullet)$, continental $(\mathbf{\square})$, and desert $(\mathbf{x})$.

processing stream. Temperature and humidity profiles along with the column integrated ozone amounts have been made available through the Meteorology, Ozone, and Aerosol (MOA) database. For the CERES Edition4A processing, MOA profiles were produced from a frozen version of the Goddard Earth Observing System data assimilation product (GEOS-5.2, also known as G5-CERES) obtained from the Global Modeling and Assimilation Office (GMAO; Rienecker et al. 2008). Having a frozen version of the GEOS dataset was essential for ensuring climate quality stability for CERES data products. Fractional cloud amounts and cloud-base heights have been made available through the Clouds subsystem within CERES processing (Minnis et al. 2010) where cloud properties were derived using highresolution imager data obtained from MODIS aboard Terra and Aqua satellites. A significant improvement to the CERES Edition-4A processing was made through the introduction of the daily total solar irradiance (TSI) data, obtained from the Solar Radiation and Climate Experiment (SORCE; Kopp and Lean 2011). These TSI measurements have provided highly precise and accurate values of total solar irradiance rather than relying on an estimated static value of $1365 \mathrm{~W} \mathrm{~m}^{-2}$. These TSI values are substantially lower than the static value, lying in the $1360-1362 \mathrm{~W} \mathrm{~m}^{-2}$ range with a median value close to $1361 \mathrm{~W} \mathrm{~m}^{-2}$. The vast majority of daily TSI values were obtained from SORCE (Kopp 2014), version 15 , data available online starting with 25 February 2003. Since the CERES Terra data record began production on 1 March 2000, the period prior to the start of SORCE data has been covered by the World Radiation
Center (WRC) Davos (Fröhlich 2012) dataset from the file composite_d41_62_0906.dat. The substantial offset between WRC and SORCE data was removed by applying an offset correction of $-4.4389 \mathrm{~W} \mathrm{~m}^{-2}$ to WRC data as suggested by providers of SORCE data (G. Kopp 2009, personal communication). The SORCE data stream was interrupted in the middle of July 2013 because of a battery problem on board the SORCE spacecraft. The CERES team decided to fill the gap by using the Royal Meteorological Institute of Belgium (RMIB) Composite data (Dewitte et al. 2004) starting on 1 July 2013. Even though SORCE data became available again as early as March 2014, CERES processing continued to use the RMIB-Composite data until 31 October 2014. Starting on 1 November 2014, CERES began using a version of SORCE data that had been revised slightly from version 15 . To maintain consistency with the earlier SORCE data, however, the most recent SORCE data have been offset in the CERES processing to match the version-15 values and have continued to be used in this manner.

\section{Surface validation data}

Ground-based measurements of surface radiative fluxes required for validation of satellite retrievals are currently being acquired by numerous high-quality networks that have come into existence during the last 20-25 years. Notable among these are BSRN (Ohmura et al. 1998), the U.S. Department of Energy Atmospheric Radiation Measurement (ARM) Program (Stokes and Schwartz 1994), and the SURFRAD (Augustine et al. 2000) 

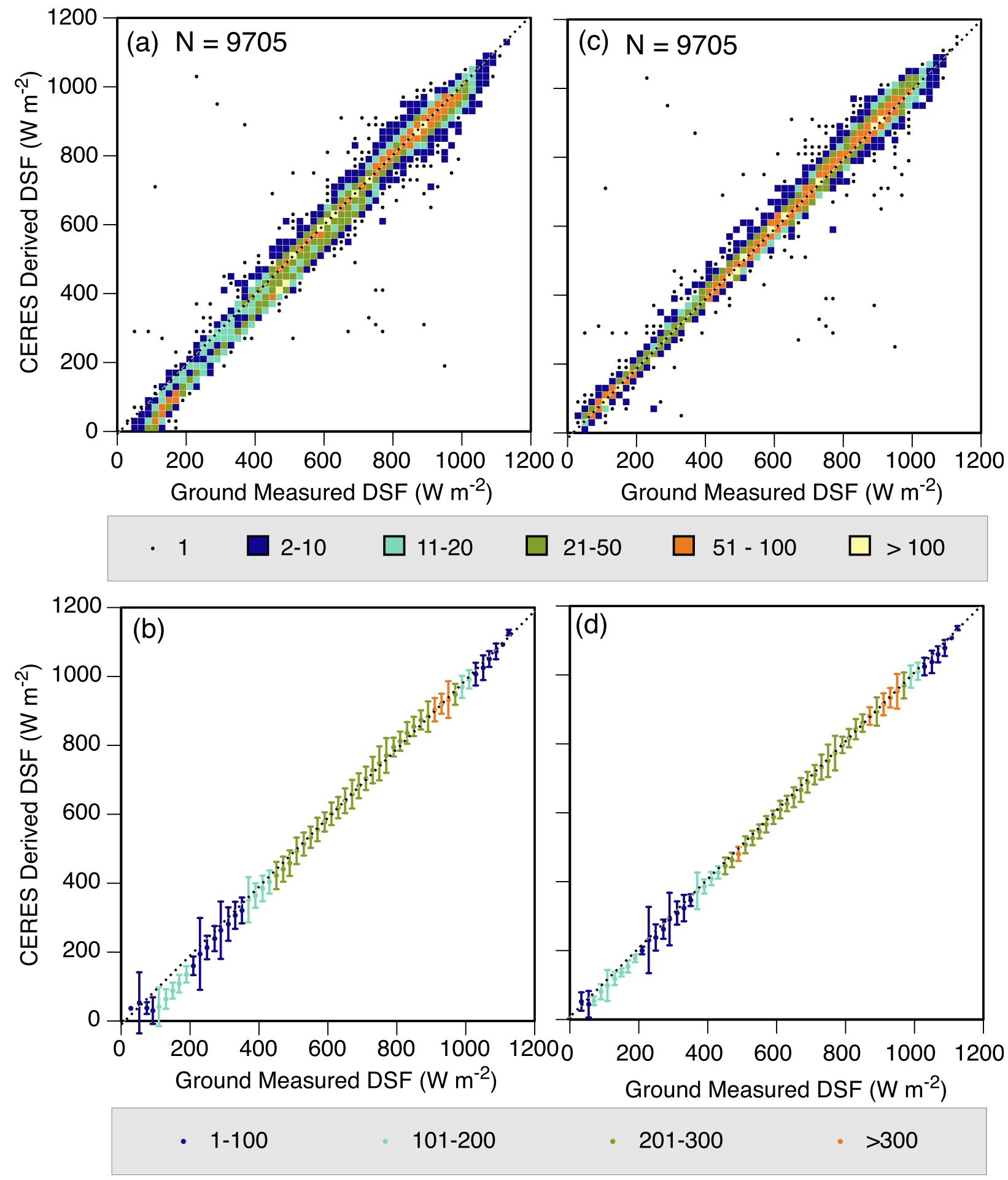

FIG. 2. Graphical comparisons between surface-measured and CERES-derived clear-sky SW fluxes from the Aqua measurements: SW model (a),(b) A and (c),(d) B for all of the surface sites used in this study, showing (top) 2D histograms that illustrate the number of coincident values found within a $20 \mathrm{~W} \mathrm{~m}^{-2}$ square bin and (bottom) the mean and standard deviation of the CERES-derived fluxes found within each $20 \mathrm{~W} \mathrm{~m}^{-2}$ interval of surface-measured fluxes. The legends associate the colors with frequency in the bins (or intervals) on the plots. The same arrangement of $2 \mathrm{D}$ histograms and mean and standard deviation plots is followed for presenting the graphical comparisons in all figures. 


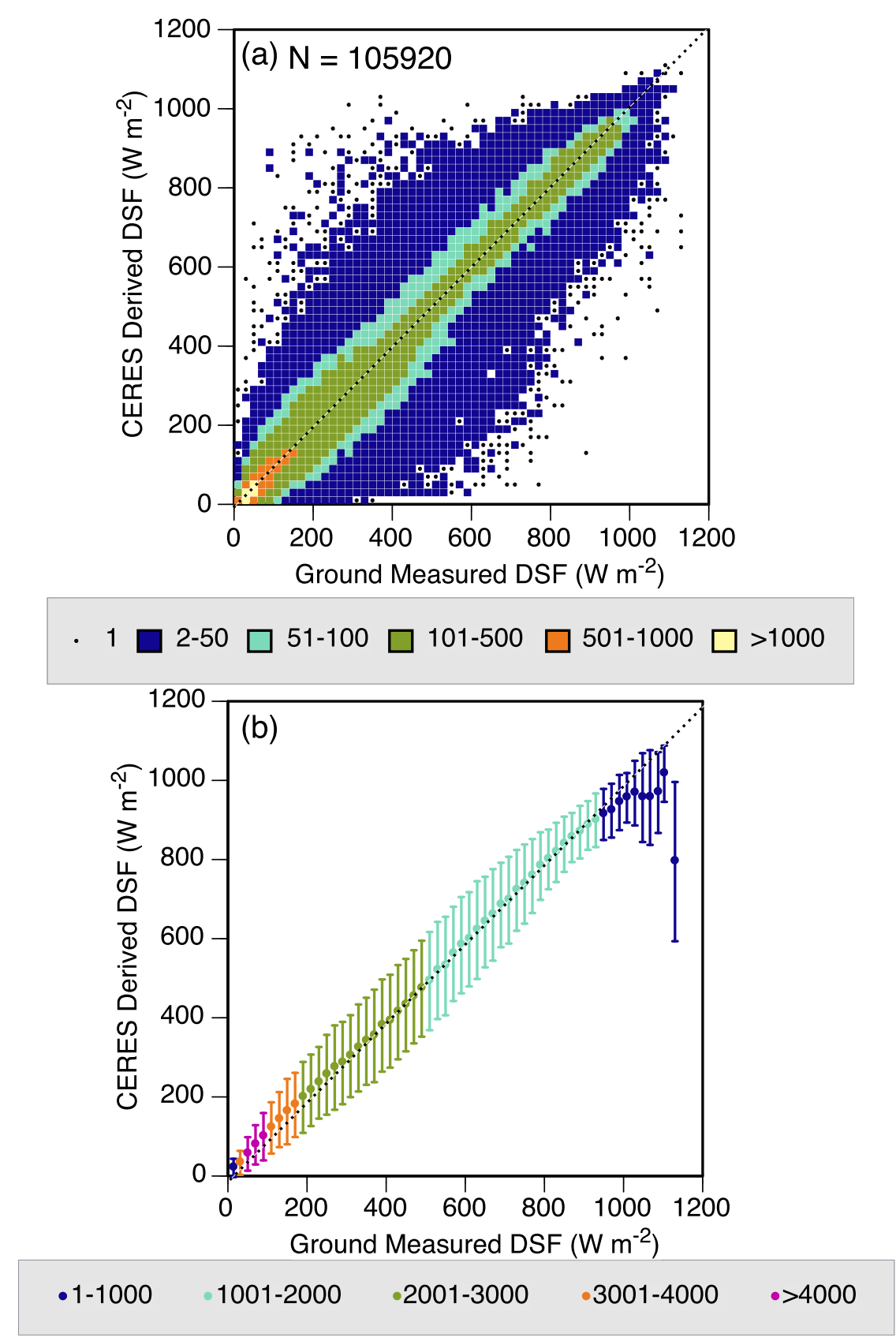

FIG. 3. Graphical comparisons between surface-measured and CERES-derived cloudy-sky SW fluxes from the Aqua measurements for SW model B.

network operated by NOAA's Global Monitoring Division (GMD). Flux measurements from 28 BSRN sites; Southern Great Plains (SGP), North Slope of Alaska (NSA), and two Tropical Western Pacific (TWP) sites from the ARM Program; and seven sites of the SURFRAD network were compiled under the CERES-ARM Validation Experiment (CAVE) banner and were made available to the worldwide science community online (https://www-cave.larc.nasa.gov). Measurements from an ocean site operated by NASA's Langley Research Center (LaRC) at the Chesapeake Lighthouse under the CERES Ocean Validation Experiment (COVE; Jin et al. 2002) were also included in the CAVE database. After discontinuation of the COVE site in 2016, that operation was shifted to the Chemistry and Physics Atmospheric Boundary Layer Experiment (CAPABLE) site already operational on the grounds of NASA LaRC. The surface sites included in the 
TABLE 1. Comparison between surface-measured and CERES-derived clear-sky SW fluxes for SW models A and B separately for Terra and Aqua satellites and footprints coming from different surface types. The global category represents all surface types combined. The columns represent the surface type (Type), the number of measurements $(n)$, the mean value of the CERES-derived fluxes for that surface type (Mean), the systematic errors (Bias), and the random errors $(\sigma)$. Percent differences inside parentheses provide a measure of relative errors. The same system has been followed for all tables.

\begin{tabular}{|c|c|c|c|c|c|c|c|c|}
\hline Type & $n$ & $\begin{array}{c}\text { Mean } \\
\left(\mathrm{W} \mathrm{m}^{-2}\right)\end{array}$ & $\begin{array}{c}\text { Bias } \\
{\left[\mathrm{W} \mathrm{m}^{-2}(\%)\right]}\end{array}$ & {$\left[\begin{array}{c}\sigma \\
{\left[\mathrm{W} \mathrm{m}^{-2}(\%)\right]}\end{array}\right.$} & $n$ & $\begin{array}{c}\text { Mean } \\
\left(\mathrm{W} \mathrm{m}^{-2}\right)\end{array}$ & $\begin{array}{c}\text { Bias } \\
{\left[\mathrm{W} \mathrm{m}^{-2}(\%)\right]}\end{array}$ & {$\left[\begin{array}{c}\sigma \\
{\left[\mathrm{W} \mathrm{m}^{-2}(\%)\right]}\end{array}\right.$} \\
\hline & \multicolumn{4}{|c|}{ Terra 4A SW model A clear sky } & \multicolumn{4}{|c|}{ Aqua 4A SW model A clear sky } \\
\hline Island & 36 & 900.3 & $30.6(3.4)$ & $141.2(15.7)$ & 26 & 868.8 & $12.8(1.5)$ & $33.4(3.8)$ \\
\hline Coastal & 1042 & 697.7 & $3.7(0.5)$ & $36.4(5.2)$ & 738 & 685.9 & $6.8(1.0)$ & $29.2(4.3)$ \\
\hline Polar & 2340 & 390.8 & $-55.8(-14.3)$ & $59.9(15.3)$ & 2856 & 379.8 & $-56.1(-14.8)$ & $62.2(16.4)$ \\
\hline Continent & 5181 & 743.6 & $-2.4(-0.3)$ & $41.9(5.6)$ & 3716 & 703.7 & $4.2(0.6)$ & $51.2(7.3)$ \\
\hline Desert & 2722 & 851.9 & $-19.4(-2.3)$ & $37.9(4.5)$ & 2065 & 813.4 & $-7.8(-1.0)$ & $27.7(3.4)$ \\
\hline \multirow[t]{2}{*}{ Global } & 11321 & 693.0 & $-16.8(-2.4)$ & $45.6(6.6)$ & 9401 & 628.5 & $-16.5(-2.6)$ & $49.5(7.9)$ \\
\hline & \multicolumn{4}{|c|}{ Terra 4A SW model B clear sky } & \multicolumn{4}{|c|}{ Aqua 4A SW model B clear sky } \\
\hline Island & 36 & 900.3 & $20.2(2.2)$ & $139.6(15.5)$ & 26 & 868.8 & $3.7(0.4)$ & $30.4(3.5)$ \\
\hline Coastal & 1047 & 698.2 & $-4.9(-0.7)$ & $35.2(5.0)$ & 743 & 685.8 & $-2.1(-0.3)$ & $27.4(4.0)$ \\
\hline Polar & 2637 & 355.4 & $-17.3(-4.9)$ & $22.1(6.2)$ & 3154 & 352.1 & $-16.6(-4.7)$ & $26.8(7.6)$ \\
\hline Continent & 5187 & 743.4 & $0.1(0.0)$ & $40.3(5.4)$ & 3724 & 703.7 & $6.3(0.9)$ & $49.9(7.1)$ \\
\hline Desert & 2732 & 851.9 & $1.3(0.2)$ & $26.6(3.1)$ & 2068 & 813.6 & $11.7(1.4)$ & $27.1(3.3)$ \\
\hline Global & 11639 & 677.4 & $-3.9(-0.6)$ & $34.2(5.1)$ & 9715 & 612.0 & $-0.6(-0.1)$ & $37.5(6.1)$ \\
\hline
\end{tabular}

CAVE database were chosen on the basis of their availability, reliability, and diversity in representing a variety of different surface types (e.g., coastal, continental, desert, island, and polar). A map showing the locations of surface sites used in this study is displayed in Fig. 1.

Many network sites provide surface insolation measurements produced by two methods. In the first method, the direct component is measured by a normal incidence pyrheliometer (NIP) and combined with diffuse component measured by a shaded pyranometer. In the other method, the total irradiance is measured by an unshaded pyranometer. In general, measurements by the first method are considered higher quality (Michalsky et al. 1999), but those can be seriously affected by tracking errors in NIP measurements and also exhibit large gaps. The unshaded measurements, although not affected by tracking problems, show far fewer gaps but are subject to cosine errors (Gupta et al. 2004). In view of this, some networks (e.g., GMD) apply strict quality controls and provide the better of the two measurements to the outside user. The pyrgeometers measuring surface LW fluxes present no such problems.

Satellite-derived and ground-measured fluxes are spatially and temporally matched prior to their comparisons. Spatial matching is ensured by using the halfwidth of a nadir-viewing footprint $(\sim 10 \mathrm{~km})$ as the maximum allowable distance between the site location and center of the footprint(s). Temporal matching is ensured by imposing the highest temporal resolution of ground site data ( 1 min for most sites) as the maximum allowable time difference between the overpass time and site measurement (Gupta et al. 2004; Kratz et al. 2010). Thus, all CERES footprint fluxes from within 1 min of the overpass time and within $10 \mathrm{~km}$ of the surface site were averaged together for comparison with the site measurement. A special consideration was made for cloudy footprint SW comparisons as those showed a large scatter contributed by the large spatial variability of clouds in many cloudy footprints. This scatter was substantially reduced by compensating for

TABLE 2. Comparisons between surface-measured and CERES-derived cloudy-sky SW fluxes for SW model B.

\begin{tabular}{|c|c|c|c|c|c|c|c|c|}
\hline Type & $n$ & $\begin{array}{c}\text { Mean } \\
\left(\mathrm{W} \mathrm{m}^{-2}\right)\end{array}$ & $\begin{array}{c}\text { Bias } \\
{\left[\mathrm{W} \mathrm{m}^{-2}(\%)\right]}\end{array}$ & {$\left[\begin{array}{c}\sigma \\
{[\mathrm{W} \mathrm{m}} \\
-2\end{array}(\%)\right]$} & $n$ & $\begin{array}{c}\text { Mean } \\
\left(\mathrm{W} \mathrm{m}^{-2}\right)\end{array}$ & $\begin{array}{c}\text { Bias } \\
{\left[\mathrm{W} \mathrm{m}^{-2}(\%)\right]}\end{array}$ & {$\left[\begin{array}{c}\sigma \\
{[\mathrm{W} \mathrm{m}} \\
-2 \\
(\%)]\end{array}\right.$} \\
\hline & \multicolumn{4}{|c|}{ Terra 4A SW model B cloudy sky } & \multicolumn{4}{|c|}{ Aqua 4A SW model B cloudy sky } \\
\hline Island & 9986 & 673.1 & $33.1(4.9)$ & $118.5(17.6)$ & 8873 & 643.8 & $39.6(6.2)$ & $126.3(19.6)$ \\
\hline Coastal & 15785 & 443.9 & $13.8(3.1)$ & $84.7(19.1)$ & 15476 & 438.2 & $12.8(2.9)$ & $82.2(18.8)$ \\
\hline Polar & 49236 & 249.9 & $-36.2(-14.5)$ & $97.2(38.9)$ & 45197 & 243.9 & $-33.4(-13.7)$ & $93.1(38.2)$ \\
\hline Continent & 33482 & 487.7 & $11.5(2.4)$ & $93.5(19.2)$ & 31567 & 474.6 & $16.5(3.5)$ & $98.1(20.7)$ \\
\hline Desert & 5238 & 707.0 & $0.3(0.0)$ & $72.2(10.2)$ & 4968 & 694.1 & $1.9(0.3)$ & 80.4 (11.6) \\
\hline Global & 113727 & 405.1 & $-7.5(-1.8)$ & $95.6(23.6)$ & 106081 & 395.5 & $-4.1(1.9)$ & $95.8(24.2)$ \\
\hline
\end{tabular}



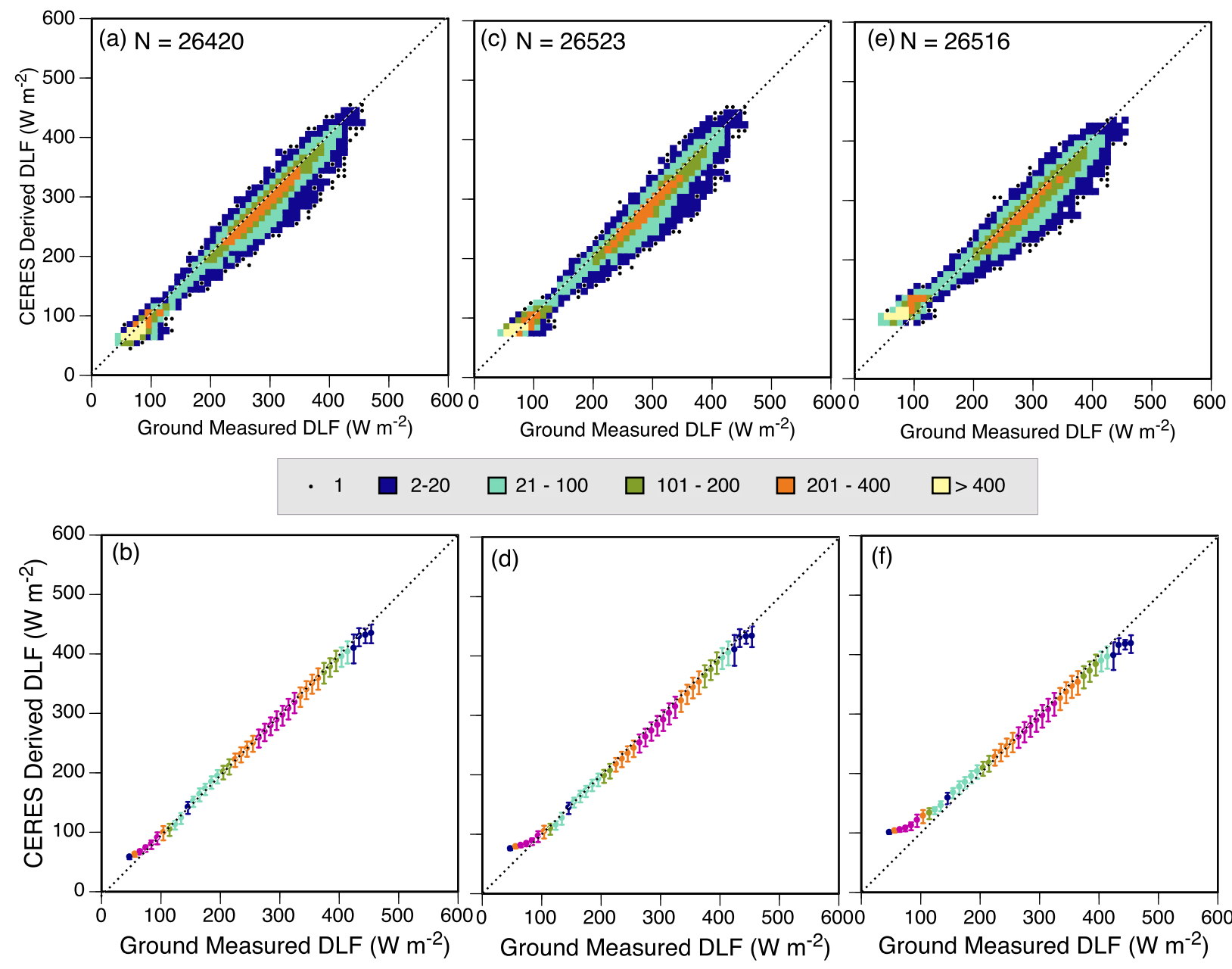

$21-100$

$101-200$

$201-400$

$\square>400$
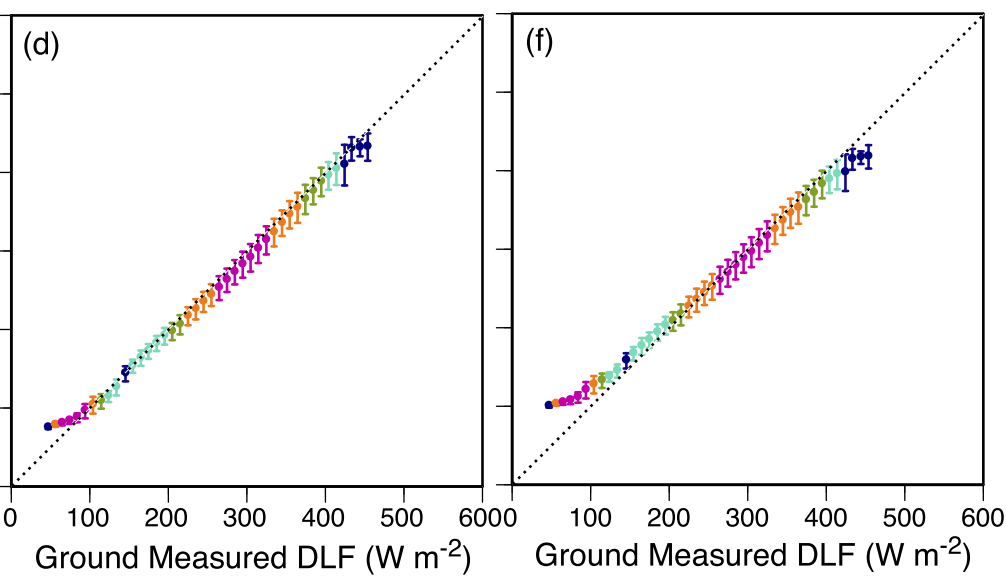

- $1-100$

$101-300$

- $301-600$

- $601-900$

- $>900$

FIG. 4. Graphical comparisons between surface-measured and CERES-derived clear-sky fluxes from Aqua measurements for LW models (a),(b) A, (c),(d) B, and (e),(f) C. The bin size in this and all LW comparisons is $10 \mathrm{~W} \mathrm{~m}^{-2}$.

the spatial variability by averaging 1-min SW measurements over longer intervals. A 60 -min interval $( \pm 30 \mathrm{~min})$ was found to be optimum and was adopted (Gupta et al. 2004).

\section{Output product and validation results}

Validation results presented here cover a period of 204 month (March 2000-February 2017) for Terra and 176 months (July 2002-February 2017) for Aqua. March 2000 and July 2002 mark the beginning of Terra and Aqua operations, respectively, and February 2017 marks the end of MODIS imager collection-5 data. Beyond February 2017, collection-5 data were superseded by collection 6 and subsequently by collection 6.1 to remedy the worsening cross-talk problem between certain MODIS channels (Platnick et al. 2017; Moeller et al. 2017) that began to affect the quality of cloud properties retrieved from the imager data. Use of cloud properties derived from collection 6.1 would have affected the climate-quality stability of the CERES product time series. As a result, Edition-4A fluxes acquired beyond February 2017 were not included in this analysis. All fluxes presented in the present study were derived using crosstrack scanning mode observations, even though both Terra and Aqua have been deployed in other scanning modes at various times.

\section{a. SW model results}

All clear-sky SW flux comparisons are shown in Fig. 2, with Aqua results for SW model A shown in Fig. 2a. 
TABLE 3. Comparison between surface-measured and CERES-derived clear-sky LW fluxes for LW models A, B, and C.

\begin{tabular}{|c|c|c|c|c|c|c|c|c|}
\hline Type & $n$ & $\begin{array}{c}\text { Mean } \\
\left(\mathrm{W} \mathrm{m}^{-2}\right)\end{array}$ & $\begin{array}{c}\text { Bias } \\
{\left[\mathrm{W} \mathrm{m}^{-2}(\%)\right]}\end{array}$ & {$\left[\begin{array}{c}\sigma \\
{\left[\mathrm{W} \mathrm{m}^{-2}(\%)\right]}\end{array}\right.$} & $n$ & $\begin{array}{c}\text { Mean } \\
\left(\mathrm{W} \mathrm{m}^{-2}\right)\end{array}$ & $\begin{array}{c}\text { Bias } \\
{\left[\mathrm{W} \mathrm{m}^{-2}(\%)\right]}\end{array}$ & {$\left[\begin{array}{c}\sigma \\
{\left[\mathrm{W} \mathrm{m}^{-2}(\%)\right]}\end{array}\right.$} \\
\hline & \multicolumn{4}{|c|}{ Terra 4A LW model A clear sky } & \multicolumn{4}{|c|}{ Aqua 4A LW model A clear sky } \\
\hline Island & 238 & 381.8 & $-2.4(-0.6)$ & $9.5(2.5)$ & 149 & 369.1 & $-1.3(-0.3)$ & $10.9(3.0)$ \\
\hline Coastal & 2535 & 302.4 & $-0.3(-0.1)$ & $10.4(3.4)$ & 2000 & 297.7 & $-0.9(-0.3)$ & $10.3(3.5)$ \\
\hline Polar & 10476 & 86.7 & $-2.6(-3.0)$ & $8.2(9.5)$ & 10808 & 88.4 & $-2.3(-2.6)$ & $8.4(9.5)$ \\
\hline Continent & 11705 & 294.9 & $-5.2(-1.8)$ & $16.5(5.6)$ & 10033 & 289.4 & $-6.3(-2.2)$ & $16.9(5.8)$ \\
\hline Desert & 4196 & 326.2 & $-6.6(-2.0)$ & $16.8(5.2)$ & 3469 & 327.9 & $-10.3(-3.1)$ & $18.4(5.6)$ \\
\hline \multirow[t]{2}{*}{ Global } & 29150 & 226.0 & $-4.0(-1.8)$ & $13.6(6.0)$ & 26459 & 213.4 & $-4.8(-2.2)$ & $13.8(6.5)$ \\
\hline & \multicolumn{4}{|c|}{ Terra 4A LW model B clear sky } & \multicolumn{4}{|c|}{ Aqua 4A LW model B clear sky } \\
\hline Island & 240 & 381.9 & $-1.1(-0.3)$ & $9.0(2.4)$ & 150 & 369.2 & $-0.9(-0.2)$ & $10.7(2.9)$ \\
\hline Coastal & 2545 & 302.4 & $-6.0(-2.0)$ & $12.8(4.2)$ & 2008 & 297.7 & $-6.6(-2.2)$ & $13.0(4.4)$ \\
\hline Polar & 10503 & 86.8 & $6.7(7.7)$ & $12.2(14.0)$ & 10826 & 88.5 & $7.0(7.9)$ & $12.4(14.0)$ \\
\hline Continent & 11743 & 294.8 & $-8.5(-2.9)$ & $18.1(6.1)$ & 10083 & 289.3 & $-9.6(-3.3)$ & $18.8(6.5)$ \\
\hline Desert & 4219 & 326.2 & $-10.5(-3.2)$ & $19.4(6.0)$ & 3495 & 328.0 & $-15.3(-4.7)$ & $22.6(6.9)$ \\
\hline \multirow[t]{2}{*}{ Global } & 29250 & 226.0 & $-3.0(-1.3)$ & $15.9(7.1)$ & 26562 & 213.6 & $-3.3(-1.5)$ & $16.6(7.8)$ \\
\hline & \multicolumn{4}{|c|}{ Terra 4A LW model C clear sky } & \multicolumn{4}{|c|}{ Aqua 4A LW model C clear sky } \\
\hline Island & 240 & 381.9 & $1.2(0.3)$ & $9.7(2.5)$ & 150 & 369.2 & $3.3(0.2)$ & $11.9(3.2)$ \\
\hline Coastal & 2542 & 302.4 & $1.7(0.6)$ & $13.4(4.4)$ & 2006 & 297.7 & $1.5(2.5)$ & $13.5(4.5)$ \\
\hline Polar & 10502 & 86.8 & $29.5(34.0)$ & $31.9(36.7)$ & 10825 & 88.5 & $30.0(33.9)$ & $32.4(36.6)$ \\
\hline Continent & 11741 & 294.8 & $-3.2(-1.1)$ & $16.8(5.7)$ & 10079 & 289.3 & $-3.9(-1.3)$ & $17.2(5.9)$ \\
\hline Desert & 4218 & 326.2 & $-12.7(-3.9)$ & $22.3(6.8)$ & 3495 & 328.0 & $-18.2(-5.6)$ & $25.6(7.8)$ \\
\hline Global & 29243 & 226.0 & $7.6(3.4)$ & $23.8(10.5)$ & 26555 & 213.6 & $8.5(4.0)$ & $25.3(11.8)$ \\
\hline
\end{tabular}

Selection of clear-sky footprints is made on the basis of satellite-derived cloud amount. Since the total number of points is very large, points on the plot were put into two-dimensional $20 \mathrm{~W} \mathrm{~m}^{-2}$ bins and the frequency of each bin was color coded on the density plot. Figure $2 b$ shows the mean and standard deviation of model derived fluxes for each $20 \mathrm{~W} \mathrm{~m}^{-2}$ interval of surface measured fluxes and provides a measure of the scatter in each flux interval. Figures $2 \mathrm{c}$ and $2 \mathrm{~d}$ show clear-sky results from SW model B. Cloudy-sky results are from SW model B only and are shown in Fig. 3. Results shown in Figs. 2 and 3 were taken from Aqua observations only to limit the number of points on each plot. Corresponding results from Terra were found to be very similar and are not presented here. Detailed statistical comparisons for both Aqua and Terra, including a breakdown of results into different surface categories (island, coastal, polar, continental, and desert), are presented in Table 1 for clear-sky fluxes from SW models A and B. The global category is defined here to represent combined results for all surface categories. Statistics on each row represent combined results for all sites in that category. Bias in all tables presented in this paper is defined as satellitederived minus ground-measured flux. Percentage differences for both systematic and random errors are provided along with flux values as measures of the relative magnitude of errors. The same system has been adopted in the discussion of all SW and LW fluxes presented in this work.
Systematic errors for SW model A clear-sky fluxes for most surface types are within $20 \mathrm{~W} \mathrm{~m}^{-2}$ (Suttles and Ohring 1986) except for the polar surface type for both satellites and for island surface type for Terra only. Corresponding errors for SW model B clear-sky fluxes are also within $20 \mathrm{~W} \mathrm{~m}^{-2}$ and generally lower than those for SW model A. Random error is very large, especially for the island surface type for both satellites but comparable to clear-sky errors found in other studies (Sun et al. 2014). Statistics for SW model B cloudy-sky fluxes are shown in Table 2. Systematic errors for cloudy-sky fluxes are larger, exceeding $35 \mathrm{~W} \mathrm{~m}^{-2}$ for the island and polar surface types. These large systematic errors may be attributable to corresponding errors in satellite cloud retrievals over island and polar surfaces. Random errors, although large for both satellites, are comparable to those for instantaneous comparisons of cloudy-sky fluxes found in other studies (Sun et al. 2012; Gautier and Landsfeld 1997) and exceed $100 \mathrm{~W} \mathrm{~m}^{-2}$ for the island surface type only.

\section{b. LW model results}

Comparisons of clear-sky LW fluxes from all models are shown in Fig. 4. These results were also taken from Aqua observations only to limit the number of points on each plot. Density plots for LW data were prepared by putting fluxes into $10 \mathrm{~W} \mathrm{~m}^{-2}$ bins since the dynamic range for LW fluxes is much smaller than for SW fluxes, while the frequency in each bin was color coded 

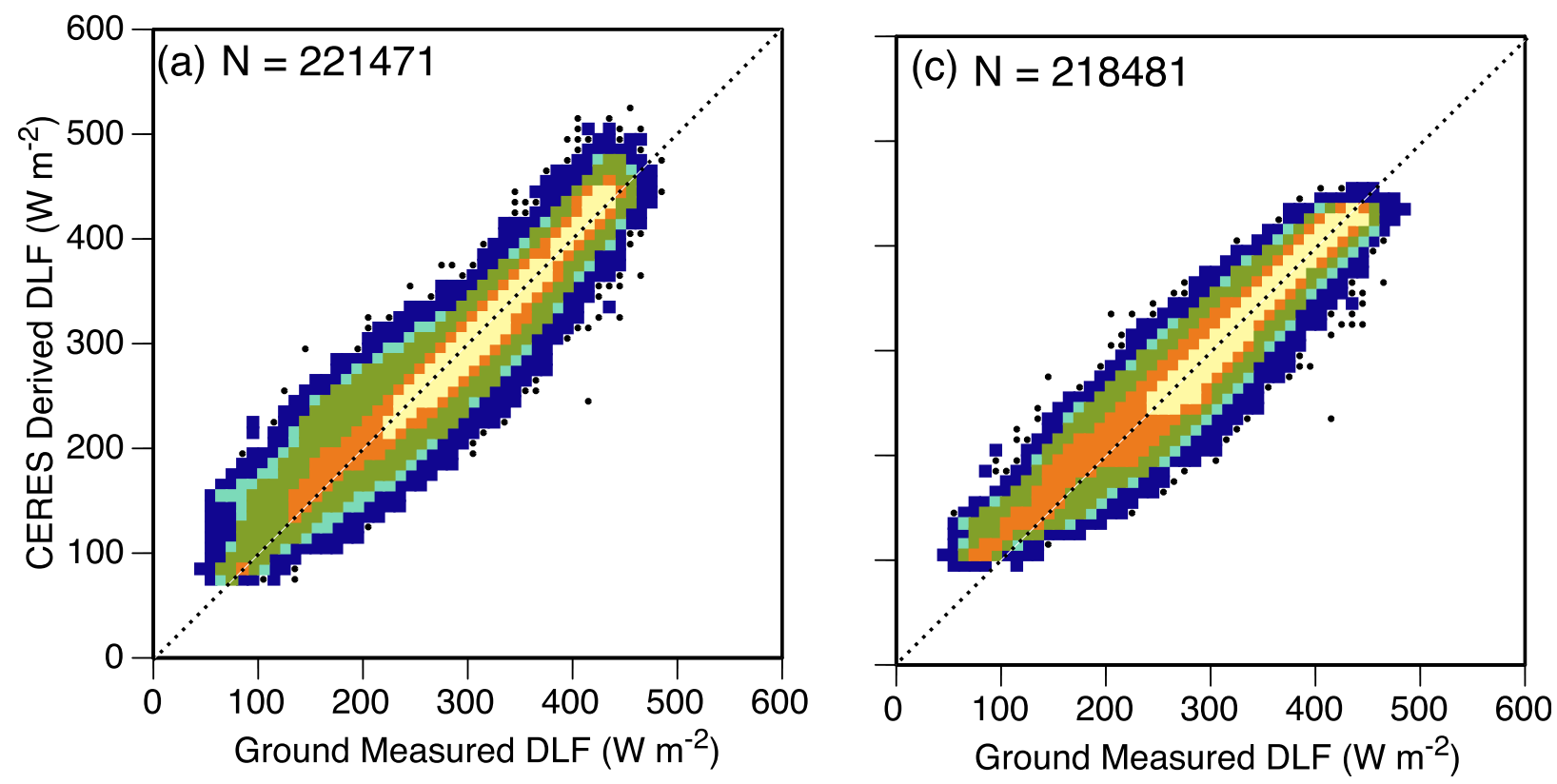
- 1
2-50
$51-100$
$101-500$
$501-1000$
$>1000$
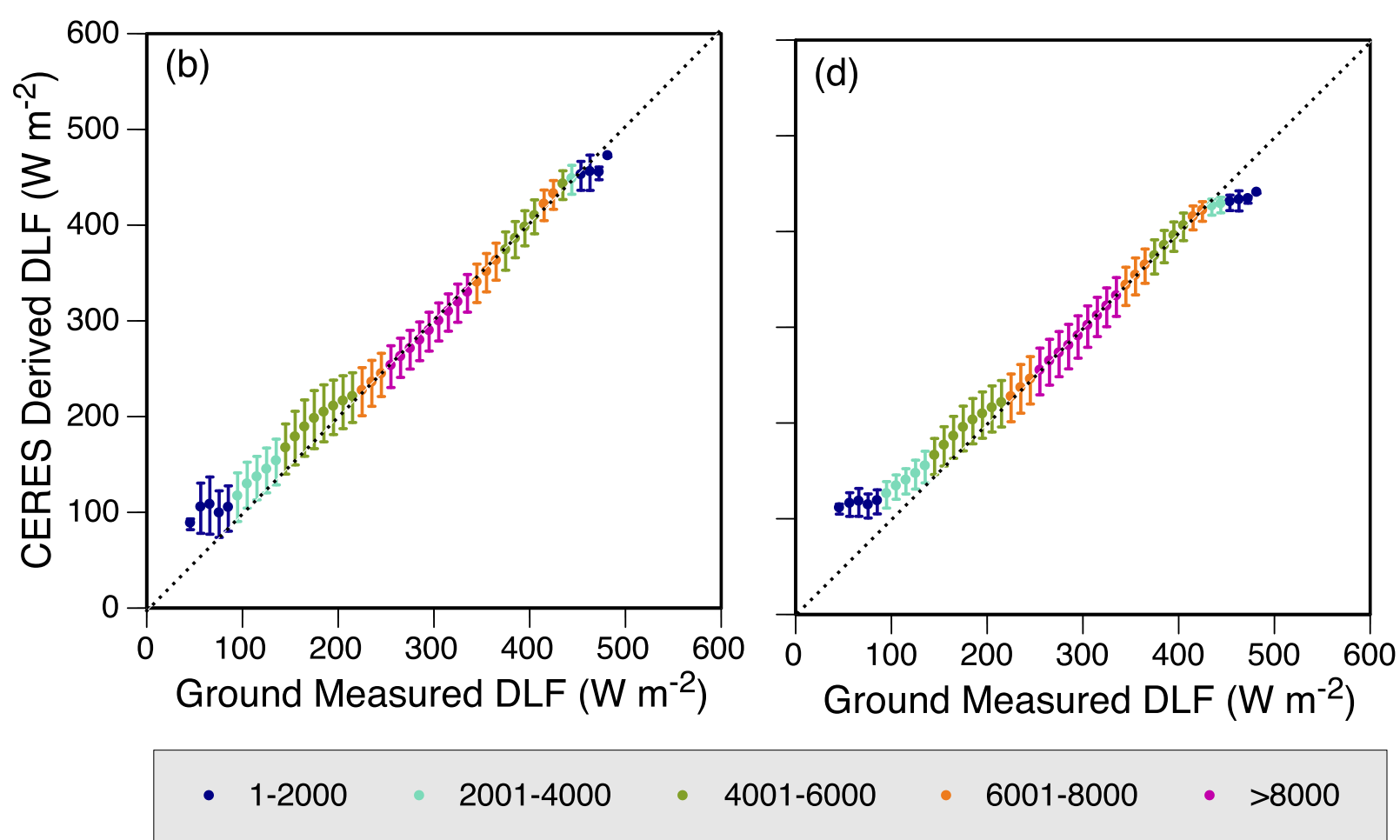

FIG. 5. Graphical comparisons between surface-measured and CERES-derived cloudy-sky fluxes from Aqua measurements for LW models (a),(b) B and (c),(d) C. 
TABLE 4. Comparisons between surface-measured and CERES-derived cloudy-sky LW fluxes for LW models B and C.

\begin{tabular}{|c|c|c|c|c|c|c|c|c|}
\hline Type & $n$ & $\begin{array}{c}\text { Mean } \\
\left(\mathrm{W} \mathrm{m}^{-2}\right)\end{array}$ & $\begin{array}{c}\text { Bias } \\
{\left[\mathrm{W} \mathrm{m}^{-2}(\%)\right]}\end{array}$ & {$\left[\begin{array}{c}\sigma \\
{\left[\mathrm{W} \mathrm{m}^{-2}(\%)\right]}\end{array}\right.$} & $n$ & $\begin{array}{c}\text { Mean } \\
\left(\mathrm{W} \mathrm{m}^{-2}\right)\end{array}$ & $\begin{array}{c}\text { Bias } \\
{\left[\mathrm{W} \mathrm{m}^{-2}(\%)\right]}\end{array}$ & {$\left[\begin{array}{c}\sigma \\
{\left[\mathrm{W} \mathrm{m}^{-2}(\%)\right]}\end{array}\right.$} \\
\hline & \multicolumn{4}{|c|}{ Terra 4A LW model B cloudy sky } & \multicolumn{4}{|c|}{ Aqua 4A LW model B cloudy sky } \\
\hline Island & 19846 & 411.3 & $5.4(1.3)$ & $16.0(3.9)$ & 17999 & 411.1 & $5.2(1.3)$ & $16.4(4.0)$ \\
\hline Coastal & 31134 & 340.8 & $2.7(0.8)$ & $18.6(5.4)$ & 30176 & 342.1 & $2.2(0.6)$ & $18.8(5.5)$ \\
\hline Polar & 109700 & 215.9 & $5.4(2.5)$ & $28.2(13.0)$ & 101786 & 216.5 & $6.1(2.8)$ & $28.6(13.2)$ \\
\hline Continent & 64732 & 320.1 & $-3.5(-1.1)$ & $22.6(7.1)$ & 60117 & 321.1 & $-4.3(-1.4)$ & $22.7(7.1)$ \\
\hline Desert & 11195 & 325.7 & $5.6(1.7)$ & $22.3(6.8)$ & 10145 & 327.8 & $0.2(0.1)$ & $20.6(6.3)$ \\
\hline \multirow[t]{2}{*}{ Global } & 236607 & 282.4 & $2.6(0.9)$ & $24.5(8.7)$ & 220223 & 283.3 & $2.4(0.8)$ & $24.7(8.7)$ \\
\hline & \multicolumn{4}{|c|}{ Terra 4A LW model C cloudy sky } & \multicolumn{4}{|c|}{ Aqua 4A LW model C cloudy sky } \\
\hline Island & 19832 & 411.3 & $0.1(0.0)$ & $13.9(3.4)$ & 17985 & 411.1 & $-0.1(-0.0)$ & $14.4(3.5)$ \\
\hline Coastal & 30875 & 341.0 & $4.9(1.4)$ & $20.5(6.0)$ & 30004 & 342.2 & $4.1(1.2)$ & $20.4(6.0)$ \\
\hline Polar & 109130 & 216.1 & $4.6(2.1)$ & $26.7(12.3)$ & 101124 & 216.7 & $5.0(2.3)$ & $26.7(12.3)$ \\
\hline Continent & 64275 & 320.3 & $-0.2(-0.0)$ & $22.5(7.0)$ & 59617 & 321.4 & $-1.2(-0.4)$ & $22.4(7.0)$ \\
\hline Desert & 11044 & 325.6 & $0.6(0.2)$ & $21.3(6.5)$ & 10025 & 327.7 & $-3.8(-1.2)$ & $21.9(6.7)$ \\
\hline Global & 235156 & 282.6 & $2.8(1.0)$ & $23.7(8.4)$ & 218755 & 283.5 & $2.3(0.8)$ & $23.7(8.4)$ \\
\hline
\end{tabular}

as before. Figures $4 \mathrm{a}, 4 \mathrm{c}$, and $4 \mathrm{e}$ show scatterplots of clear-sky fluxes for the three models (A, B, and C) while corresponding mean and standard deviation plots are shown in Figs. 4b, 4d, and 4f, respectively. Figures $4 \mathrm{~b}, 4 \mathrm{~d}$, and $4 \mathrm{f}$ clearly show the substantial departure of flux averages from the $45^{\circ}$ line for very low fluxes for all models. This departure can be attributed to the deficiency in all models in handling extremely low water vapor amounts in the atmosphere. Although present in all models, this deficiency is most prominent in model C. LW results from Terra were also found to be very similar and are not presented here.

Details of statistical comparisons are shown in Table 3 for both Aqua and Terra clear-sky fluxes including the breakdown of results for different surface types and the global category. Clear-sky LW model A results for both Terra and Aqua (Table 3, top third) show small systematic errors of less than $\pm 7.0 \mathrm{~W} \mathrm{~m}^{-2}$ for nearly all surface types with the exception of deserts for Aqua for which the bias reached a value slightly greater than $10 \mathrm{~W} \mathrm{~m}^{-2}$. Corresponding comparisons from LW model B (Table 3, middle third) also show systematic errors in both Terra and Aqua results to be within $10 \mathrm{~W} \mathrm{~m}^{-2}$ except for the desert surface type for which biases for both satellites reached in the $10-15 \mathrm{~W} \mathrm{~m}^{-2}$ range. Results for LW model C (Table 3, bottom third) show that biases for both desert and polar surface types are substantially larger for Terra, reaching as high as $30 \mathrm{~W} \mathrm{~m}^{-2}$. Specific causes of these large errors may be difficult to identify, although large errors in scene identification remain a possible reason.

Cloudy-sky fluxes are available from LW models B and $\mathrm{C}$ only. Their density scatterplots are shown in Figs. 5a and $5 \mathrm{c}$ along with the standard deviation plots

TABLE 5. Comparison between surface-measured and CERES-derived clear-sky LW fluxes for LW models A, B, and C. Statistics are reported separately for daytime and nighttime footprints and together for all footprints.

\begin{tabular}{|c|c|c|c|c|c|c|c|c|}
\hline Type & $n$ & $\begin{array}{c}\text { Mean } \\
\left(\mathrm{W} \mathrm{m}^{-2}\right)\end{array}$ & $\begin{array}{c}\text { Bias } \\
{\left[\mathrm{W} \mathrm{m}^{-2}(\%)\right]}\end{array}$ & {$\left[\mathrm{W} \mathrm{m}^{-2}(\%)\right]$} & $n$ & $\begin{array}{c}\text { Mean } \\
\left(\mathrm{W} \mathrm{m}^{-2}\right)\end{array}$ & $\begin{array}{c}\text { Bias } \\
{\left[\mathrm{W} \mathrm{m}^{-2}(\%)\right]}\end{array}$ & {$\left[\begin{array}{c}\sigma \\
{\left[\mathrm{W} \mathrm{m}^{-2}(\%)\right]}\end{array}\right.$} \\
\hline & \multicolumn{4}{|c|}{ Terra 4A LW model A clear sky } & \multicolumn{4}{|c|}{ Aqua 4A LW model A clear sky } \\
\hline Day & 11917 & 260.8 & $-1.4(-0.5)$ & $13.3(5.1)$ & 9979 & 243.0 & $-2.5(-1.0)$ & $12.8(5.3)$ \\
\hline Night & 17233 & 201.8 & $-5.9(-2.9)$ & $13.8(6.8)$ & 16480 & 195.5 & $-6.1(-3.1)$ & $14.3(7.3)$ \\
\hline \multirow[t]{2}{*}{ Day-night } & 29150 & 226.0 & $-4.0(-1.8)$ & $13.6(6.0)$ & 26459 & 213.4 & $-4.8(-2.2)$ & $13.8(6.5)$ \\
\hline & \multicolumn{4}{|c|}{ Terra 4A LW model B clear sky } & \multicolumn{4}{|c|}{ Aqua 4A LW model B clear sky } \\
\hline Day & 11969 & 260.9 & $-2.8(-1.1)$ & $14.1(5.4)$ & 10040 & 243.2 & $-3.2(-1.3)$ & $14.7(6.1)$ \\
\hline Night & 17280 & 201.9 & $-3.2(-1.6)$ & $17.1(8.5)$ & 16522 & 195.7 & $-3.4(-1.7)$ & $17.7(9.0)$ \\
\hline \multirow[t]{2}{*}{ Day-night } & 29249 & 226.0 & $-3.0(-1.3)$ & $15.9(7.1)$ & 26562 & 213.6 & $-3.3(-1.5)$ & $16.6(7.8)$ \\
\hline & \multicolumn{4}{|c|}{ Terra 4A LW model C clear sky } & \multicolumn{4}{|c|}{ Aqua 4A LW model C clear sky } \\
\hline Day & 11963 & 260.9 & $5.0(1.9)$ & $19.7(7.5)$ & 10034 & 243.1 & $6.2(2.5)$ & $22.6(9.3)$ \\
\hline Night & 17279 & 201.9 & $9.5(4.7)$ & $26.2(13.0)$ & 16521 & 195.7 & $9.9(5.1)$ & $26.8(13.7)$ \\
\hline Day-night & 29242 & 226.0 & $7.6(3.4)$ & $23.8(10.5)$ & 26555 & 213.6 & $8.5(4.0)$ & $25.3(11.8)$ \\
\hline
\end{tabular}



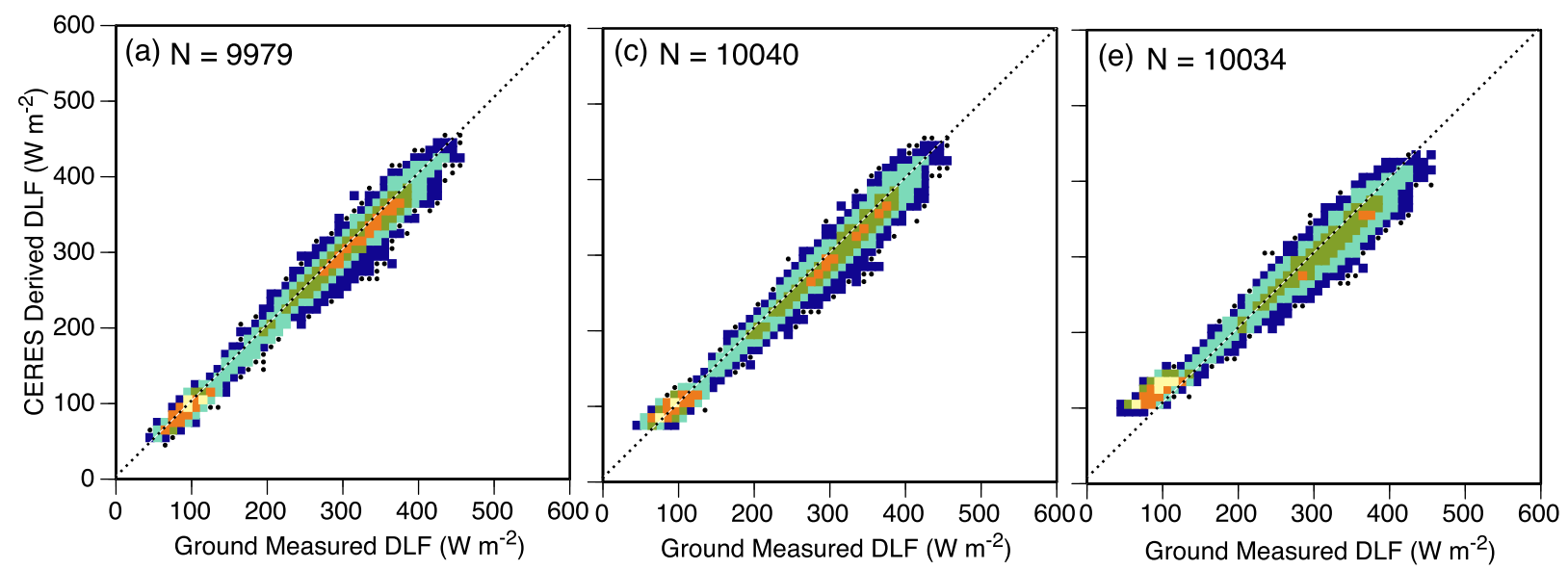

\section{. $1 \square 2-10 \square 11-50 \quad \square 51-100 \quad \square 101-200 \quad \square>200$}
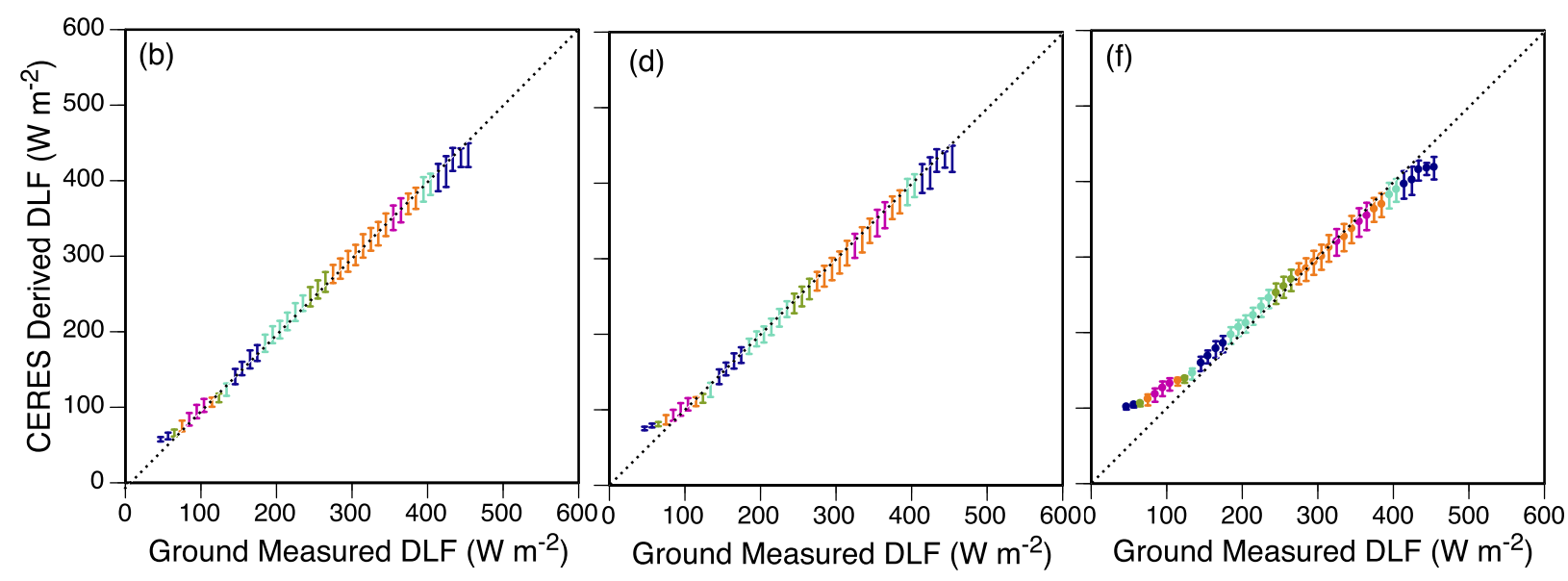

- $1-100$

$101-200$

- 201-300

- $301-400$

- $>400$

FIG. 6. Graphical comparisons between surface-measured and CERES-derived daytime clear-sky fluxes from Aqua measurements for LW models (a),(b) A, (c),(d) B, and (e),(f) C.

in Figs. $5 b$ and $5 d$, respectively. Figures $5 b$ and $5 d$ show, for both models, substantial deviation from the $45^{\circ}$ line in the low flux range, indicating overestimation by the models. Once again, this overestimation is more severe in model $\mathrm{C}$ than in model B. Statistical results for cloudy-sky fluxes are presented in Table 4. Systematic errors for both models are very small, all staying with in $10 \mathrm{~W} \mathrm{~m}^{-2}$. Random errors for both models are larger, mostly between 20 and $30 \mathrm{~W} \mathrm{~m}^{-2}$, with the highest values occurring for polar surface types. These larger random errors can be attributed to the high spatial and temporal variability of clouds along with other reasons that impart errors to clearsky fluxes.

An earlier study on the validation of CERES-derived surface fluxes (Gupta et al. 2004) showed an $8-10 \mathrm{~W} \mathrm{~m}^{-2}$ difference in systematic errors between daytime and nighttime clear-sky LW flux comparisons. The primary cause of these difference was determined to be a negative bias during daytime and positive bias during nighttime in surface temperatures in the input meteorological data taken from GEOS-4 reanalysis product. Based on that experience, systematic and random errors for clearsky LW fluxes were carefully examined in this study separately for daytime and nighttime for global (combined for all surface types) results. Statistical results of that study are presented in Table 5 for both daytime and nighttime for LW models A, B, and C. Scatterplots for clear-sky LW fluxes in this study are shown in Fig. 6 for daytime only. A comparative look at day and night systematic errors shows that those are small and negative for models A (Table 5, top third) and B (Table 5, 
middle third) while being slightly larger and positive for model C (Table 5, bottom third). A look at random errors for clear-sky LW fluxes shows that, whereas random errors for models $\mathrm{A}$ and $\mathrm{B}$ are in the $13-18 \mathrm{~W} \mathrm{~m}^{-2}$ range, those for model $\mathrm{C}$ are in the $23-27 \mathrm{~W} \mathrm{~m}^{-2}$ range. While there is no clear indication of large day-night differences in systematic errors, as was seen in Edition-2B results (Gupta et al. 2004), model C clear-sky LW fluxes show substantially larger systematic and random errors relative to the other two models.

\section{Summary and conclusions}

The main objective of this study was to validate the derived surface fluxes and the algorithms used to derive them. To accomplish that objective, surface SW and LW fluxes for clear and cloudy skies were derived on an instantaneous footprint basis under the SOFA segment of CERES project using TOA measurements, cloud parameters derived from MODIS collection-5 radiances and aerosol properties derived from MATCH products. Temperature and humidity profiles and ozone came from the CERES MOA, which is primarily based on GEOS-5 reanalysis products. All of these constituted the inputs for the radiative transfer algorithms used for deriving surface fluxes. The period for this validation covers 204 months (March 2000-February 2017) for Terra and 176 months (July 2002-February 2017) for Aqua. The cutoff date was imposed by the discontinuation of MODIS collection 5 at the end of February 2017 and the desire in this validation to use a totally consistent dataset for which all algorithms and inputs remain unchanged throughout the period.

Clear-sky fluxes derived by SW model A (Li et al. 1993b) met the established accuracy criteria for four of the five surface types but not for polar surfaces where random errors far exceeded the established criteria (Table 1, top half). Clear-sky SW model B fluxes follow a similar pattern although error magnitudes are much smaller except for the large random error over island-type sites for Terra observations (Table 1, bottom half). Cloudy-sky SW fluxes provided only by SW model B (Table 2) exhibit larger systematic errors for the island and polar surfaces and a large random error only for islands. Island site comparisons are especially prone to large errors because of the spatial mismatch between point observation from sites and gridbox values from satellite retrievals caused by frequent formation of low clouds over islands during certain times of the day (Long and McFarlane 2012). Random errors for other surface types are similar to those found in other studies (Sun et al. 2012, 2014; Gautier and
Landsfeld 1997). Potential causes of these errors were discussed in the previous section.

Systematic errors for LW models A and B are very modest, exceeding $10 \mathrm{~W} \mathrm{~m}^{-2}$ only for desert surfaces. For LW model C, however, systematic errors are much larger for desert surfaces and even larger for polar surfaces. Also, while random errors for models A and $\mathrm{B}$ are mostly within $20 \mathrm{~W} \mathrm{~m}^{-2}$, those for model $\mathrm{C}$ are in excess of $20 \mathrm{~W} \mathrm{~m}^{-2}$ for desert surfaces and exceed $30 \mathrm{~W} \mathrm{~m}^{-2}$ for polar surfaces. For cloudy-sky fluxes, both systematic and random errors are modest for both models B and C. In summary, both SW and LW models A have limited value because these are clear-sky-only models. Models B, both SW and LW, perform well for both clear and cloudy conditions and will likely be preferred models for future studies. LW model C does not perform well for clear conditions.

Acknowledgments. This research has been supported by the NASA CERES project. The CERES instantaneous Single Scanner Footprint (SSF) Ed4A data are available online (https://ceres.larc.nasa.gov/ products-info.php? product $=$ SSF-Level2). The NASA Langley Atmospheric Sciences Data Center processed the SSF data. The surface validation data are also available online (https://www-cave.larc.nasa.gov/ pages/sfcobs.html). For land-based observations, we include sites from the Baseline Surface Radiation Network (BSRN), NOAA's Global Monitoring Division (GMD) and SURFRAD network, and the U.S. Department of Energy's Atmospheric Radiation Measurement (ARM) Program. The authors also thank D. A. Rutan (SSAI) for providing the CAVE database and Joanne Saunders for providing the formatting of the equations in this document.

\section{REFERENCES}

Augustine, J. A., J. J. DeLuisi, and C. N. Long, 2000: SURFRAD-A national surface radiation budget network for atmospheric research. Bull. Amer. Meteor. Soc., 81, 2341-2357, https://doi.org/10.1175/1520-0477(2000)081<2341: SANSRB $>2.3 . \mathrm{CO} ; 2$.

Collins, W. D., P. J. Rasch, B. E. Eaton, B. V. Khattatov, J.-F. Lamarque, and C. S. Zender, 2001: Simulating aerosols using a chemical transport model with assimilation of satellite aerosol retrievals: Methodology for INDOEX. J. Geophys. Res., 106, 7313-7336, https://doi.org/10.1029/2000JD900507.

Deepak, A., and H. E. Gerber, Eds., 1983: Report of the expert's meeting on aerosols and their climatic effects. WMO Rep. WCP-55, $107 \mathrm{pp}$.

Dewitte, S., D. Crommelynck, and A. Joukoff, 2004: Total solar irradiance observations from DIARAD/VIRGO. J. Geophys. Res., 109, A02102, https://doi.org/10.1029/2002JA009694.

Fröhlich, C., 2012: Total solar irradiance observations. Surv. Geophys., 33, 453-473, https://doi.org/10.1007/s10712-011-9168-5. 
Gautier, C., and M. Landsfeld, 1997: Surface solar radiation flux and cloud radiative forcing for the Atmospheric Radiation Measurement (ARM) Southern Great Plains (SGP): A satellite, surface observations, and radiative transfer model study. J. Atmos. Sci., 54, 1289-1307, https://doi.org/10.1175/ 1520-0469(1997)054<1289:SSRFAC $>2.0 . C O ; 2$.

GCOS, 2003: The second report on the adequacy of the global observing system for climate in support of the UNFCCC. WMO/TD 1143, GCOS-82, 85 pp., https://library.wmo.int/ doc_num.php?explnum_id=3931.

Gupta, S. K., 1989: A parameterization for longwave surface radiation from Sun-synchronous satellite data. J. Climate, 2, 305-320, https://doi.org/10.1175/1520-0442(1989)002<0305: APFLSR $>2.0 . \mathrm{CO} ; 2$.

__, W. L. Darnell, and A. C. Wilber, 1992: A parameterization for longwave surface radiation from satellite data: Recent improvements. J. Appl. Meteor., 31, 1361-1367, https://doi.org/10.1175/1520-0450(1992)031<1361:APFLSR> 2.0.CO;2.

, D. P. Kratz, P. W. Stackhouse Jr., and A. C. Wilber, 2001: The Langley Parameterized Shortwave Algorithm (LPSA) for surface radiation budget studies, version 1.0. NASA Tech. Publ. NASA/TP-2001-211272, 31 pp., https://ntrs.nasa.gov/ archive/nasa/casi.ntrs.nasa.gov/20020022720.pdf.

_ _ - _ A. C. Wilber, and L. C. Nguyen, 2004: Validation of parameterized algorithms used to derive TRMM-CERES surface radiative fluxes. J. Atmos. Oceanic Technol., 21, 742-752, https://doi.org/10.1175/1520-0426(2004)021<0742: VOPAUT $>2.0 . \mathrm{CO} ; 2$.

,,-- P. W. Stackhouse, A. C. Wilber, T. Zhang, and V. E. Sothcott, 2010: Improvement of surface longwave flux algorithms used in CERES processing. J. Appl. Meteor. Climatol., 49, 1579-1589, https://doi.org/10.1175/2010JAMC2463.1.

Hess, M., P. Koepke, and I. Schult, 1998: Optical Properties of Aerosols and Clouds: The software package OPAC. Bull. Amer. Meteor. Soc., 79, 831-844, https://doi.org/10.1175/ 1520-0477(1998)079<0831:OPOAAC > 2.0.CO;2.

Inamdar, A. K., and V. Ramanathan, 1997: On monitoring the atmospheric greenhouse effect from space. Tellus, 49B, 216230, https://doi.org/10.3402/tellusb.v49i2.15963.

Jin, Z., T. P. Charlock, and C. K. Rutledge, 2002: Analysis of the broadband solar radiation and albedo over the ocean surface at COVE. J. Atmos. Oceanic Technol., 19, 1585-1601, https://doi.org/ 10.1175/1520-0426(2002)019<1585:AOBSRA>2.0.CO;2.

Kato, S., N. G. Loeb, F. G. Rose, D. R. Doelling, D. A. Rutan, T. E. Caldwell, L. Yu, and R. A. Weller, 2013: Surface irradiances consistent with CERES-derived top-of-atmosphere shortwave and longwave irradiances. J. Climate, 26, 2719-2740, https:// doi.org/10.1175/JCLI-D-12-00436.1.

_ , and Coauthors, 2018: Surface irradiances of Edition 4.0 Clouds and the Earth's Radiant Energy System (CERES) Energy Balanced and Filled (EBAF) data product. J. Climate, 31, 45014527, https://doi.org/10.1175/JCLI-D-17-0523.1.

Kopp, G., 2014: An assessment of the solar irradiance record for climate studies. J. Space Wea. Space Climate, 4, A14, https:// doi.org/10.1051/swsc/2014012.

— diance: Evidence and climate significance. Geophys. Res. Lett., 38, L01706, https://doi.org/10.1029/2010GL045777.

Kratz, D. P., S. K. Gupta, A. C. Wilber, and V. E. Sothcott, 2010: Validation of the CERES Edition-2B surface-only flux algorithms. J. Appl. Meteor. Climatol., 49, 164-180, https://doi.org/ 10.1175/2009JAMC2246.1.
Li, Z., and L. Garand, 1994: Estimation of surface albedo from space: A parameterization for global application. J. Geophys. Res., 99, 8335-8350, https://doi.org/10.1029/94JD00225.

_, H. G. Leighton, and R. D. Cess, 1993a: Surface net solar radiation estimated from satellite measurements: Comparisons with tower observations. J. Climate, 6, 1764-1772, https://doi.org/ 10.1175/1520-0442(1993)006<1764:SNSREF > 2.0.CO;2.

,,-- K. Masuda, and T. Takashima, 1993b: Estimation of SW flux absorbed at the surface from TOA reflected flux. J. Climate, 6, 317-330, https://doi.org/10.1175/1520-0442(1993)006<0317: EOSFAA $>2.0 . \mathrm{CO} ; 2$.

Loeb, N. G., S. Kato, K. Loukachine, and N. Manalo-Smith, 2005: Angular distribution models for top-of-atmosphere radiative flux estimation from the Clouds and the Earth's Radiant Energy System instrument on the Terra satellite. Part I: Methodology. J. Atmos. Oceanic Technol., 22, 338 351, https://doi.org/10.1175/JTECH1712.1.

_ N. Manalo-Smith, W. Su, M. Shankar, and S. Thomas, 2016: CERES top-of-atmosphere Earth radiation budget climate data record: Accounting for in-orbit changes in instrument calibration. Remote Sens., 8, 182-195, https://doi.org/10.3390/ rs8030182.

—_, and Coauthors, 2018: Clouds and the Earth's Radiant Energy System (CERES) Energy Balanced and Filled (EBAF) topof-atmosphere (TOA) Edition-4.0 data product. J. Climate, 31, 895-918, https://doi.org/10.1175/JCLI-D-17-0208.1.

Long, C. N., and S. A. McFarlane, 2012: Quantification of the impact of Nauru Island on ARM measurements. J. Appl. Meteor. Climatol., 51, 628-636, https://doi.org/10.1175/JAMC-D-110174.1.

Menzel, W. P., and Coauthors, 2008: MODIS global cloud-top pressure and amount estimation: Algorithm description and results. J. Appl. Meteor. Climatol., 47, 1175-1198, https:// doi.org/10.1175/2007JAMC1705.1.

Michalsky, J., E. Dutton, M. Rubes, D. Nelson, T. Stoffel, M. Wesley, M. Splitt, and J. DeLuisi, 1999: Optimal measurement of surface shortwave irradiance using current instrumentation. J. Atmos. Oceanic Technol., 16, 55-69, https://doi.org/10.1175/1520-0426(1999) $016<0055$ :OMOSSI $>2.0 . \mathrm{CO} ; 2$.

Minnis, P., and Coauthors, 2010: CERES Edition-2 cloud property retrievals using TRMM VIRS and Terra and Aqua MODIS data-Part II: Examples of average results and comparisons with other data. IEEE Trans. Geosci. Remote Sens., 49, 44014430, https://doi.org/10.1109/TGRS.2011.2144602.

Moeller, C., R. Frey, E. Borbas, W. P. Menzel, T. Wilson, A. Wu, and X. Geng, 2017: Improvements to Terra MODIS L1B, L2, and L3 science products through using crosstalk corrected L1B radiances. Proc. SPIE, 10402, 1040200, https://doi.org/ 10.1117/12.2274340.

Ohmura, A., and Coauthors, 1998: Baseline Surface Radiation Network (BSRN/WCRP): New precision radiometry for climate change research. Bull. Amer. Meteor. Soc., 79 , 2115-2136, https://doi.org/10.1175/1520-0477(1998)079<2115: BSRNBW $>2.0 . \mathrm{CO} ; 2$.

Platnick, S. K., and Coauthors, 2017: The MODIS cloud optical and microphysical products: Collection 6 updates and examples from Terra and Aqua. IEEE Trans. Geosci. Remote Sens., 55 , 502-525, https://doi.org/10.1109/TGRS.2016.2610522.

Rasch, P. J., N. M. Mahowald, and B. E. Eaton, 1997: Representations of transport, convection, and the hydrologic cycle in chemical transport models: Implications for the modeling of short-lived and soluble species. J. Geophys. Res., 102, 28127-28138, https:// doi.org/10.1029/97JD02087. 
Rienecker, M. M., and Coauthors, 2008: The GEOS-5 Assimilation System-Documentation of Versions 5.0.1, 5.1.0 and 5.2.0. NASA Tech. Memo. NASA/TM-2008-104606, Vol. 27, 118 pp., https://gmao.gsfc.nasa.gov/pubs/docs/GEOS5_104606-Vol27.pdf.

Rose, F. G., D. A. Rutan, T. Charlock, G. L. Smith, and S. Kato, 2013: An algorithm for constraining of radiative transfer calculations to CERES-observed broadband top-of-atmosphere irradiance. J. Atmos. Oceanic Technol., 30, 1091-1106, https:// doi.org/10.1175/JTECH-D-12-00058.1.

Stokes, G. M., and S. E. Schwartz, 1994: The Atmospheric Radiation Measurement (ARM) Program: Programmatic background and design of the cloud and radiation testbed. Bull. Amer. Meteor. Soc., 75, 1201-1221, https://doi.org/ 10.1175/1520-0477(1994)075<1201:TARMPP>2.0.CO;2.

Su, W., J. Corbett, Z. Eitzen, and L. Liang, 2015a: Next-generation angular distribution models for top-of-atmosphere radiative flux calculation from CERES instruments: Methodology. Atmos. Meas. Tech., 8, 611-632, https://doi.org/10.5194/amt-8-611-2015. and -2015 b: Next-generation angular distribution models for top-of-atmosphere radiative flux calculation from CERES instruments: Validation. Atmos. Meas. Tech., 8 , 3297-3313, https://doi.org/10.5194/amt-8-3297-2015.

Sun, Z., J. Liu, X. Zeng, and H. Liang, 2012: Parameterization of instantaneous global horizontal irradiance: Cloud-sky component. J. Geophys. Res., 117, D14202, https://doi.org/10.1029/ 2012JD017557.

_- X. Zeng, J. Liu, H. Liang, and J. Li, 2014: Parametrization of instantaneous global horizontal irradiance: Clear-sky component. Quart. J. Roy. Meteor. Soc., 140, 267-280, https://doi.org/ 10.1002/qj.2126.
Suttles, J. T., and G. Ohring, Eds., 1986: Surface radiation budget for climate applications. NASA Reference Publ. 1169, 132 pp., https://ntrs.nasa.gov/archive/nasa/casi.ntrs.nasa.gov/ 19860019102.pdf.

Wielicki, B. A., B. R. Barkstrom, E. F. Harrison, R. B. Lee III, G. L. Smith, and J. E. Cooper, 1996: Clouds and the Earth's Radiant Energy System (CERES): An Earth Observing System experiment. Bull. Amer. Meteor. Soc., 77, 853-868, https://doi.org/ 10.1175/1520-0477(1996)077<0853:CATERE>2.0.CO;2.

Wilber, A. C., D. P. Kratz, and S. K. Gupta, 1999: Surface emissivity maps for use in satellite retrievals of longwave radiation. NASA Tech. Publ. NASA/TP-1999-209362, 35 pp., https://eosweb.larc.nasa.gov/sites/default/files/project/calipso/ Wilber.NASATchNote99.pdf.

Wild, M., and E. Roeckner, 2006: Radiative fluxes in the ECHAM5 general circulation model. J. Climate, 19, 3792-3809, https:// doi.org/10.1175/JCLI3823.1.

_- A. Ohmura, H. Gilgen, and E. Roeckner, 1995: Validation of general circulation model radiative fluxes using surface observations. J. Climate, 8, 1309-1324, https://doi.org/10.1175/ 1520-0442(1995)008<1309:VOGCMR > 2.0.CO;2.

Zhou, Y., and R. D. Cess, 2001: Algorithm development strategies for retrieving the downwelling longwave flux at the Earth's surface. J. Geophys. Res., 106, 12 477-12 488, https://doi.org/ 10.1029/2001JD900144.

- D. P. Kratz, A. C. Wilber, S. K. Gupta, and R. D. Cess, 2007: An improved algorithm for retrieving surface downwelling longwave radiation from satellite measurements. J. Geophys. Res., 112, D15102, https://doi.org/10.1029/ 2006JD008159. 